\title{
Functions of Indirectness in American Idol Judges' Comments
}

\author{
Raynesta Mikaela Indri Malo \\ raynestaindri8@gmail.com \\ Agribusiness Department, Universitas Kristen Wira Wacana Sumba
}

\begin{abstract}
Indirectness is one of the most efficient ways to communicate each other. People use indirectness in communication for different purposes. The most discussed and discovered purpose across cultures is for politeness; people use language in indirect way to prevent hurting other's feelings. In many cultures, indirectness is highly valued because saving face and harmony in social relationships are highly respected. This study is a descriptive study which is aimed at analyzing the functions or the purpose of using indirectness or indirect language in one of the rarely discussed realm of language use, a TV show, specifically, American Idol. The findings also reveal the strategies used in order to perform the functions. The data is limited to the audition of American Idol season eight (8) which was held in 2009. There were 7 recordings for the 8 cities of audition. The total number of data used in this study was 50 indirect comments. The result shows that there were 3 functions of the use of indirectness in the comments of the judges. The functions were (i) being ironic, (ii) being polite, and (iii) giving hints.
\end{abstract}

Keywords: indirectness, politeness, judges' comments

\section{Introduction}

Language is generally a tool or media of communication, used by people to communicate each other. However, communication in general is culturally dependent. It means that using language in communication is also culturally dependent; one speaks according to the acceptable rules or customs in his or her society. Cultural aspect that is related to or is conveyed through language is politeness (and impoliteness). Each society has its own parameter of measuring politeness and determines its own way or rule of how to be polite, such as in communication. Most societies measure politeness (and impoliteness) using the scale of directness and indirectness. For instance, a boy who says 'open the window' to his teacher is regarded to be impolite since he uses or employs a direct request. In a society like Indonesian society, the younger a person is, the more indirect use of language he or she should use when speak to older people. The above expression should be, for example, 'would you mind opening the window'?

Besides in every day communication, directness and indirectness is also found in various contexts of communication such as in letters, radio broadcasting, and TV shows. This study is aimed at analyzing functions of indirectness in one of the most popular TV shows in America, American Idol, with the focus on the indirectness in the judges' comments in the contest. This study is a descriptive study which tries to describe the natural use of language, in this case the use of indirect speech or indirectness in English in giving comments to other people's performance in a TV show. The description is shown in the analysis of data which consist of sentences and any lexical item as part of the comments. The main source of the data is the recording of the American Idol show. Number 
of data is limited to the audition of the $8^{\text {th }}$ season of American Idol (2009). This field is chosen because the study investigating indirectness in this field has not been done yet, even the study of how language is used in general in this field is also rarely found.

\section{Review on Pragmatic Theory}

Pragmatics is the systematic study of meaning by virtue of, or dependent on the use of language (Huang 2007: 2). It means that pragmatic is concerned with the meaning of language when the language is used in particular context. Pragmatics studies the relationship between context of use, sentence meaning, and speaker's meaning. According to Yule, pragmatics is the study of the relationship between the linguistic forms and the users of the forms (Yule, 1996: 4). Only pragmatics (compare to syntax and semantics) concerns with the presence of human in the analysis of language use. The benefit of studying the use of language through pragmatics is that one can learn and discuss about people's intended meanings, their assumptions, and their purposes or goals, and also kinds of action that they are performing (such as offering, requesting, etc). Generally, the central topics of inquiry in pragmatics include deixis and distance, reference and inference, presupposition and entailment, cooperation and implicature, speech acts and events, and also politeness.

In line with Yule, Leech says that meaning in pragmatics is defined relative to speaker or user of the language. That is why he calls the relation as triadic relation; between language, its meaning, and its speakers. Pragmatics is then defined as the study of meaning in relation to speech situations. For that reason, it is also important to know the aspects of speech situation. They are (i) the addresser or the addressee - any individual involved in the interaction -, (ii) the context of an utterance the physical or social setting of an utterance as well as any background knowledge assumed to be shared by speaker and hearer and which contributes to hearer's interpretation of what speaker means by a given utterance-, (iii) the goal(s) of an utterance, (iv) illocutionary act of an utterance, and $(\mathrm{v})$ the utterance as a product of a verbal act (1983: 13).

Hoye (2006) emphasizes that applying pragmatics stresses the problems of the use of language that arise in social contexts where the failure to communicate successfully may lead to social exclusion and disadvantage. It also aims to reveal the hidden relationship between social power and language use, for example by helping people understand the power of language to discriminate others (in Mey, 2009: 26).

In relation to the topic of this study, pragmatics is applied to study of the use of language in the level of group of people, who specifically use language in a public area. By applying pragmatics, the element of language use, such as the indirect use of language can be investigated. Pragmatics is used to find the relation between the context (the show of American Idol), the speakers (the judges) and the speakers' meaning in using language, especially the indirect use. Based on the context, the show of American Idol is a commercial TV show and has been distributed and watched worldwide. The judges are those people who have been working in the show business for many years, for example as singer, producer, song writer, and also talent scout.

\section{Review on Indirectness Theory}

Indirectness refers to a speech act in which the expressed meaning of an utterance does not match the speaker's implied or intended meaning. An indirect illocutionary act requires the speaker's and the listener's shared knowledge on particular topics in the conversation and the ability to make interpretations on the listener's part (Thomas 1995: 119).

As a communication style, indirectness is found in everyday interaction. Indirectness is used as a more useful method in communication. For example to perform different expression such as giving hints, avoiding confrontation, joking, being ironic, or expressing politeness by saving the face of either speaker. In many cultures, mainly in the Asian or eastern cultures, indirectness is 
appreciated because saving face and harmony in social relationships are highly respected.

Besides for politeness reason, there are also studies such as of Colston and Huang that report the use of indirectness as the tool for offensiveness. There are claims which state that indirectness is related to the opposite of politeness, impoliteness and rudeness (Srinarawat, 2005). According to Culpeper et.al, impoliteness is the use of strategies that are designed to attack face and thereby cause social conflict and disharmony (2003: 1545).

\section{Discussion}

Basically, in the show, the tasks of the judges are first giving comments on the singing performance of the contestants and then making decision whether a contestant is going to Hollywood or not. The judges have their individual rights to give any comments. Some are in the direct forms and some are in the indirect forms. In the indirect forms, one that is being analyzed here, there are different types of functions conveyed by the comments. From the analysis of the data, there are 3 functions of the indirectness in the comments given by the American Idol judges, namely (i) being ironic, (ii) being polite, and (iii) giving hints. The findings also reveal the strategies used in order to perform particular functions.

\section{Being Ironic}

According to Leech, irony is a secondorder principle, building on the politeness principle. It allows the listener to understand the offensive intention of the speaker's remark (1983). It means that irony is basically used to convey politeness when speakers basically want to say something impolite or offensive. In the analysis of the indirect speech in American Idol, generally the speakers use irony to convey sarcasm or offensive attitude or comment toward the hearer, such as to insult or to criticize the hearer. The comments that function at conveying the irony are (3), (4), (6), (7), and (17).
Sentence (3) 'Okay. All right, I just wondered if you turned up on the right show or not' is a comment to the contestant, Elijah Scarlet who sings indistinctively with his deep voice. Simon, rather than commenting on the contestant's performance, asks the contestant a series of question on the contestant's understanding and awareness of the purpose of the show (see conversation (a)). After asking those questions, Simon ironically says 'All right, I just wondered if you turned up on the right show or not' which indirectly means that in Simon's opinion, it is not the right thing to do for the contestant to join such competition regarding his bad performance and his lack of ability in singing. This indirect speech act conveys irony to insult the contestant that the contestant has come to the wrong show or that it is a wrong the decision for the contestant to have a willing to join such show.

In sentence (4) 'I'll tell you what it sounded like. It sounded like a cat jumping off the Empire State building, and the noise it would make before it hit the floor. If that makes sense', Simon is being ironic when commenting the performance of Chelsea Marquardt. The irony can be seen through the use of simile, that Simon compares Chelsea's voice to that of a cat. People facing this kind of sentence should have knowledge about the world, in this case about the sound of a cat jumping off a very high building such as the Empire State building. The sound that the cat makes before hitting the floor is the cat's scream with its unclear voice. The sound, if it can be described, is the terrible one. By saying the sentence, Simon indirectly says that Chelsea's voice is terrible.

Sentence (6) 'Have you ever sung?' is the comment given by Kara to the contestant, Dalton Powell, who sings indistinctively with his little voice. Although the comment is in the interrogative form, it is not really a question. Instead, it is used to convey irony of the condition at the time. Dalton comes to an audition for a singing competition with totally having no skill in singing. The judge, Kara, rather than directly saying the fact that Dalton cannot sing at all, asking the question 'have you ever sung?' which literally means that Kara wants Dalton to share his 
experience. This question however also implies something like 'have you ever sung? Because the way you sing shows that you are someone with no experience in singing.' Indirectness in this comment is used to convey irony to insult the contestant.

Sentence (7) George, have you ever done this before? Auditioned, or sang in public? is Simon's comment after watching the performance of George Ramirez. This comment is similar to sentence (6) above. By asking this question, Simon is ironically says that George is someone who has never been singing in front of people and it is not good if he wants to join American Idol because experience and skill are highly required.

In the sentence (17) 'Yeah, hopefully soon', Simon is expressing his hope that the contestant, Tara Matthews, will fly away or go away soon from the audition room. Simon says this sentence right after Tara singing the song Someday I'll Fly Away. The way Simon chooses the moment to say the sentence implies his hope. By saying the sentence Simon also indirectly wants to say that the performance of the contestant is not good at all and therefore it is better for the contestant to go away from the audition room.

The discussion above shows that in being ironic, speakers or the judges is insulting the contestant by saying offensive sentences. The irony itself created at the time the judges say something which is basically means the opposite of it. For instance, the comment 'have you ever sung?' is basically indirect speech of saying 'you have never sung for you entire life'. It is can be concluded then that the use of indirectness is to convey rudeness, deliberately or not, through the use of irony. This rudeness then which sometimes raises anger of the contestants who are being insulted by the judges. The insulted contestants sometimes express their anger through swear words or curse, crying, or even doing anarchist actions.

\section{Being Polite}

Politeness can described as the attempt to save face of another (Brown and Levinson, 1987). In order to save other's face, people usually use indirectness or indirect speech act in saying something even if it is something that the hearer does not like, such as criticizing the hearer or rejecting the hearer request, or in the case of American Idol, rejecting the contestants of getting on the next step of the competition process. There are 6 sentences, (5), (14), (20), (22), (23) and (25), taken as example of politeness as the function of indirectness.

The first is sentence (5) 'You're probably just like a cool bar singer, you know? You're singing in bars and in the clubs and doing your thing. I'm not sure it's right for this, man, for $m e^{\prime}$. Randy gives this comment to the contestant, Matt Bridesky who used to be a bar singer. Randy is being polite in his use hedges 'I'm not sure' to mitigate the effect of his intention. The rather strong version of this sentence is for example, 'I think this is not right for you'. Randy is also being polite in the way that he gives or states the good sides of Matt's work as a bar-singer, and then states the reality that American Idol is not right for Matt.

In (14), 'I think you would do a lot of things very well, but not singing. I mean that in a compliment-- in a complimentary way' Simon is giving his ideas on Tatiana Del Toro's performance in a polite way. From the comment, it can be inferred that according to Cowell, singing is not good or suitable for Tatiana. However, Cowell gives his comments indirectly by first give compliment to Tatiana's talents. This is theoretically will lessen the effect of face threatening act toward the hearer. The effect will be different if the comment is given in a direct way such as "you cannot sing, I think" or "you are a terrible singer"; it will attack the face of the hearer.

The expressive sentence (20) 'We didn't mean to hurt your feelings, honey' Kara's statement when commenting the performance of Tara Matthews, who sings Someday I'll Fly Away. Before Kara gives the comment, the contestant is first being commented by Simon who hopes that the contestant will go away soon from the audition room since her performance (from the voice, outfit and the song choice) is 
horrendous or not good at all. Kara is basically agrees with Simon that Tara does not deserve to be allowed to go to the next step. However Kara does not state it directly. Kara is being polite to reject the contestant in the way that rather than saying or giving comment on Tara's performance, Kara only says that sentence which indirectly means that the judges have to reject Tara and if the rejection hurts Tara, the judges basically did not mean it.

In sentence (22) 'You are beautiful, and I'm sorry that you had to hear some stuff that was harsh, but it's the way these auditions go, and we have to pass', Paula is also trying to be polite when rejecting the contestant Chelsea Marquardt, who, by Simon, is being compared to the cat. Before Paula gives this comment, Kara also gives similar comments which aim not to break the heart of the contestant after being commented in such a rude way by Simon. Paula expresses her feeling of regretful that the contestant cannot go to Hollywood using more polite form than just simply saying the last clause 'we have to pass'. Paula considers her partner's in conversation feeling that she says the good thing about the contestant, says sorry for the bad things said to the contestant, and then finally says that it is the fact that the audition is not good and the contestant does not succeed. Through this sentence, Paula is also encouraging Chelsea's heart by saying that Chelsea is beautiful. By firstly states this encouraging statement, Paula lessens the effect of the FTA or face threatening acts in this case the rejection toward Chelsea.

Paula states (23) when commenting the contestant, Randy Madden, at the time of voting. Rather than saying 'yes' or 'no', Paula states 'You know what, I do appreciate your story, and I know that this is hard for you' which then arises a question from Simon Cowell 'yes or no?'. Simon's question clearly shows that Paula does not say what she wants to say directly, whether it is a yes or a no. At that time, Randy starts to cry and beg to the judges to let him go to Hollywood. Paula basically has the same answer with other judges, that it is a no for Randy Madden. However, Paula wants to be more polite because she considers the feeling of the contestant that might be hurt after finding out that he cannot make his dream comes true.

In (25) 'I think, Michael, you're quite interesting, but your voice isn't' Simon is being polite in saying that the contestant's voice is not good or interesting. Simon's politeness is revealed through the use of the first clause ' $I$ think, Michael, you're quite interesting' which basically gives praises to the contestant. After giving praise, Simon then says the truth that Michael's voice is not as interesting as himself.

From the above discussion, it can be seen that indirect speech is used when the judge want to reject or eliminate the contestant but at the same time want to do it in polite way that might not hurt the contestant. The typical structure of indirectness that conveys politeness is that the main clause which contains the truth (that the contestant will be eliminated) is placed as the second or third clause in a complex sentence. The first or opening clause is usually contains praising or good things about the contestant. This is done to lessen the effect of the FTA on the side of the hearer.

\section{Giving Hints}

A hint, as it is defined by the Collins COBUILD Dictionary, is a suggestion or advice which is given indirectly. Generally, people give hint by saying something indirectly to express their feeling. It is clear then that the use of indirectness is to give hint. In the case of American Idol, it is the judges who give hint to the contestants through their comments. There are 13 indirect sentences in the comments of the American Idol judges which are used to give hints

Sentence (1) 'The competition would sorely miss you if you weren't in it' is the comment given by Paula Abdul at the time the judges have to vote whether the contestant, Emily Whynne-Hughes is going to Hollywood for the next round or not. Instead of saying 'yes', as what Simon Cowell and Randy Jackson do, Paula says 'The competition would sorely miss you if you weren't in it'. In this way, Paula gives an 
indirect answer to the contestant's performance. Her answer functions at giving hint to the contestant that she is going through to Hollywood based on her good performance. American Idol would miss the contestant if she were not in it. Therefore she is accepted. Paula Abdul expressed her opinion by asserting her opinion.

Sentence (2) 'And I don't think you've got star quality. And I don't think you ever will' is a comment from Simon to the contestant, Randy Madden who wants to be a rock-star because confidently thinks that he is a rockstar in a box that need to be opened. However, Simon thinks that Randy's performance is very wimpy and Randy himself is like a drama queen because he suddenly burst into tears when Simon seems to dislike him or his performance. That is why Simon says that Randy does not have a star quality because of his wimpy and dramaqueen characters. By saying this, Simon indirectly says that it is a wrong decision for Randy to come to the audition since he does not have a star quality. Simon gives hint to Randy that American Idol is not the right place for him because he will never be a star (rock-star).

The next is (8) 'I think you would struggle within the parameters of this competition'. Simon gives this comment to Michael Perelli who sings nervously since he is not allowed to sing with his guitar. Nervousness adds the weakness of Michael's performance. Simon, by saying that sentence is giving hint to Michael that since his voice and performance are not good enough to be in a competition as American Idol, he will struggle a lot if he goes to the next round.

When commenting the performance of Rich Kagel, Simon says (9) 'You're never ever, in a million billion years, gonna win a show like this', which literally means that Rich will never win any singing competition even in a million billion years. Indirectly, through the sentence, Simon wants to say that Rich's performance and voice are not good enough. By using hyperbole, or using language in an excessive way, Simon wants to give hints that Rich will not succeed the audition, not only in 2009 but also in many years in the future.
The sentence (10) 'Jessika, I can swim, but I'm not going to win ten Olympic medals at the Olympic Games'. This sentence is stated by Simon when commenting the performance of Jessika Byer who is really confident of her experiences and winning on some singing competition out of 700. Based on Jessika's performance, Simon questions how Jessika can win those competitions. By saying that sentence, Simon is giving hint to Jessika that she will be eliminated. According to Simon, one may be able to swim but it is just not enough to win a swimming competition. It is also the case in singing competition. Jessika can sing, but it is not enough for her to win or even to be accepted in American Idol.

Paula gives comment (11) 'You really gotta work on your voice' when commenting the performance of Lea Marie Golde whose voice seems to be not fully develop yet. This sentence is a directive that Paula is giving her advice to Lea. However, by saying this sentence, Paula also indirectly says that Lea will not go through the next round. Paula is giving hint that Lea does not succeed in the audition.

Paula also gives hint when saying (12) 'But it's--you know what, I think you should be in a band, I really $d o$ ' at that time the judges have to vote whether Randy Madden will go through the next round or not. Rather than saying 'yes' or 'no', Paula states (12) which indirectly means 'no'. By saying that it is better for Randy to be in a band, Paula gives hint that it is not good for Randy to be in American Idol.

Through (13) 'Michael, five years wouldn't make any difference' Simon is giving hints to the contestant who asks for a second audition after 5 minutes. By saying this, Simon gives hints that he (Simon) does not want the contestant to have a double audition because not only in 5 minutes, but even in 5 years the contestant will not be able to sing any better. The comment indirectly says that the contestant fails in the audition.

The sentence (15) '(Aquila: Well, can I try it one more time, please?) Aquila, we've done the entire album.' is a comment given by Simon Cowell to Aquila Eskew-Gholston who 
sings her own songs. Aquila is a woman who thinks that to be a good singer, one should has good knowledge on the body system, especially on how to employ one's parts of body to produce good voice and to sing well. Her performance is not good and then she asks to sing another original song. However, Simon Cowell does not want Aquila does that. Simon, rather than saying "don't (do that)", saying "we've done the entire album," which actually give hint that Simon does not want to hear Aquila sing anymore because usually, if an entire album is done, it means that all the song have been sung and there is no need to hear anymore song. Cowell gives his opinion indirectly by giving hints.

Sentence (16) 'Good, that's the direction I want you to take. Right, then right' is Simon's comment to the contestant, Dana Murano who does not sing very well in the audition. Simon thinks that Dana cannot sing the big song as the one form Chaka Khan. Then Dana says 'Oh, I will take as much direction as you guys want'. Simon, however, replies with an answer that seems to be not expected by Dana, rather than saying or giving advice of what Dana should do. By saying (16) Simon is indirectly leads Dana to the door to get out of the room. This comment also a hint that Dana fails in the audition.

In (18) 'Um, did you actually deliver the resignation letter? (Yes, I did.) I think you may need to retract it, Adeola, based on that performance' Simon is giving hint to the contestant Adeola that she will not go to the next round. Adeola is a girl, who on the day before the audition gave the resignation letter to the office where she used to work for to pursue her dream in American Idol. By saying that Adeola has to retract the resignation letter based on her performance, Simon indirectly says that Adeola is eliminated. Therefore, she needs her job back.

Simon gives comment (19) 'Okay. Can we have another song?' when the contestant, Joel Contreras has just finished the first line of his song. Basically, Joel appearance is somewhat ridiculous with his big iPod made of cardboard which he calls as human iPod. Comment (19) is basically a hint that the way
Joel sings is terrible so he should sing another song.

The last sentence (21) 'I'm glad you sang bubbly' is expressing Paula's pleasure of Anne Marie Boskovich's singing the song which is matching her voice. By saying that sentence, Paula is not only expressing her pleasure but also hinting that the contestant's performance is good supported by the choice of song. The result in the end shows that Anne is accepted to go to Hollywood for the next round.

\section{Conclusion}

After having the analysis of the indirectness in the American Idol judges' comments, it is found that there are 3 functions of the use of indirectness in the comments of the judges. The functions are (i) being ironic, (ii) politeness or being polite, and (iii) giving hints. The first function is done by stating something but meaning the opposite. As irony is the second principle in the Politeness Principle, the discussion about irony is also being related to politeness. By using irony, a speaker is basically using polite expression when he/she wants to say something impolite or offensive. The data shows that the judges use irony to convey, deliberately or not, an offensive attitude toward the contestants, i.e. to insult the contestants. There are two ways through which irony is achieved, (i) the use of questions; and (ii) the use of sentences that have relation to the title of the song.

The second function is done through the use of typical pattern found in this study, that is by stating positive followed by the truth which is usually negative (compliments facts pattern). The judges perform politeness through the use of indirectness especially when they have to eliminate the contestants. By doing it indirectly, it then lessens the possible risk, i.e. the contestant get angry of being eliminated. There are several ways through which politeness is achieved, (i) the use of hedges, (ii) statement of regret ('sorry), (iii) giving compliments or praises, (compliments - facts pattern) and (iv) the use of statement with consideration of the contestants' feelings. 
The last function of indirectness is for giving hints. It is found that the judges use indirectness to give hint about the contestants' auditions (either good or bad) as well as about their voting for the contestant (either accepted or eliminated). There are several ways through which this function (giving hint) is achieved, (i) giving advice or order, (ii) the use of conditional if, (iii) using words such as 'chance' or 'shot' which indicates opportunity in the next round (especially to say yes), (iv) hyperbole, (v) the use of comparison, (vi) making prediction, (vii) criticizing, etc.

\section{References}

Culpeper, J., Derek B., and Anne W. 2003. "Impoliteness re-visited: With special reference to dynamic and prosodic aspects." Journal of Pragmatics Vol. 35.

Hoye, L. F. 2009. "Applying Pragmatics." Concise Encyclopedia of Pragmatics. 2 ${ }^{\text {nd }}$ ed. Ed. Jacob L. Mey. Oxford: Elsevier.

Huang, Yan. 2007. Pragmatics. Oxford: Oxford University Press.

Leech, Geoffrey. 1983. Principles of Pragmatics. London: Longman.

Mey, Jacob L. 2006. "Pragmatics: Overview." Concise Encyclopedia of Pragmatics. 2 ${ }^{\text {nd }}$ ed. Ed. Jacob L. Mey. Oxford: Elsevier.

Srinarawat, Deeyu. 2005. "Indirectness as a politeness strategy of Thai speakers." Broadening the Horizon of Linguistic Politeness. Ed. Lakoff, Robin T. and Sachiko Ide. Amsterdam: John Benjamins Publishing Company.

Thomas, Jenny. 1995. Meaning in Interaction: An Introduction to Pragmatics. New York: Longman.

Yule, George. 1996. Pragmatics. Oxford: Oxford University Press. 